\title{
Early years education in Qatar: The good practice guide in theory and practice
}

\author{
Al-Thani, Tamader \\ Department of Psychological Sciences, Qatar University, Qatar (tamader.althani@qu.edu.qa)
}

Al-Muftah, Esraa

Department of Educational Sciences, Qatar University, Qatar (ealmuftah@qu.edu.qa)

Romanowski, Michael H

Department of Educational Sciences, Qatar University, Qatar (michaelhr@qu.edu.qa)

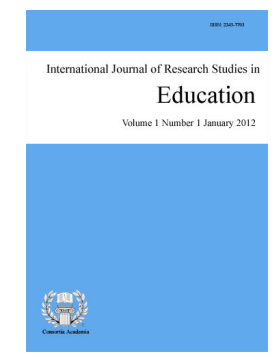

ISSN: 2243-7703 Online ISSN: 2243-7711

OPEN ACCESS

Coughlin, Chris

Department of Psychological Sciences, Qatar University, Qatar (ccoughlin@qu.edu.qa)

Abuelhassan, Hadeel

Department of Educational Sciences, Qatar University, Qatar(ha082519@student.qu.edu.qa)

\section{Abstract}

Qatar's massive education reform, Education for a New Era has dramatically shaped the educational landscape by implementing professional and curriculum standards and introducing best pedagogical practices at all levels. The current concern with Qatar's educational reform is not so much the adopted policies but rather the implementation of these policies into classroom practices. This study examines several kindergartens in Qatar to explore the issues and concerns regarding the implementation of the Supreme Education Counsel's The Early Years Education Good Practice Guide (GPG); a policy document providing evidence-based, needs based, culturally responsive appropriate early childhood teaching methods and materials. This research study includes focus groups with 22 kindergarten teachers/academic coordinators and classroom observations. By providing what Fullan (2000) terms an "inside, inside out and outside story", we examine both the practices being utilized in kindergartens and obstacles that prevent teachers from implementing the GPG from the perspective of teachers and other early childhood school personnel. Finally, we provide possible recommendations regarding the implementation of the GPG.

Keywords: education; educational reform; early childhood education; policy implementation; educational practices 


\section{Early years education in Qatar: The good practice guide in theory and practice}

\section{Introduction}

The development of Qatar's Ministry of Education in the 1950's has played a dominant role in developing and overseeing educational structure and policies including early childhood education (Althani \& Romanowski, 2013). In 2001, Qatar's government realized the current educational system lacked high-quality outcomes based on benchmarked international league tables (for example, Trends in International Mathematics and Science Study (TIMMS) and the Program for International Student Assessment (PISA) (Brewer, et. al., 2007). In response a nonprofit research organization, RAND, was hired to conduct a critical examination of Qatar's K-12 education system. The comprehensive assessment identified weaknesses in Qatar's educational system. First, the current system failed to provide a vision of quality education and the support structures needed for quality education were lacking. There was a highly centralized system in place with no performance indicators, and the little performance data provided to schools had limited potential for change because school leaders and teachers lacked the authority to make changes (Brewer et. al, 2007). Second, the educational assessment also indicated the curriculum was outmoded, highly controlled, emphasized rote memorization and appeared unchallenging for students (Brewer, et. al, 2007). Third, the educational stakeholders lacked a shared vision and this partly due to the rigid top-down decision-making policy structure. Finally, the finances guided to education were few evidenced by the poor physical conditions of schools, the lack of professional development opportunities and teachers' low salaries. Therefore any current reform would not be effective with incremental changes but rather reform in this context demanded a substantial system change and a well-developed and defined implementation plan. These findings led to four system-changing options and the Qatari government decided to develop a charter school model where education is decentralized and various Independent schools would be developed throughout Qatar. Hence, Education for a New Era (EFNE), a designed reform to transform Qatar's schools into a world-class competitive education system began to take shape (Brewer et al., 2007).

To improve successful implementation, the Supreme Education Council (SEC) was developed and assigned the task of ensuring the efficient and effective functioning of schools and teachers based on rigorous international standards (Althani \& Romanowski, 2013). The role of the SEC is one of support for the Independent schools including developing curriculum standards and school system goals. In addition, the SEC provides opportunities for teachers and school leaders to engage in professional development and also has the responsibility to assess school performance and student progress. In what follows, we provide findings from a preliminary study that examines how teachers are implementing the policies and practices demanded by the Qatar Educational Reform. The purpose of this study is not to develop a comprehensive understanding of policy implementation but rather to begin the process of understanding how educational reform is being implemented and provide insight into future areas of study.

\section{Kindergartens in Qatar}

The SEC set up the first kindergartens as part of the Independent school system during the 2008-2009 academic year. As of the 2014-2015 school year, there are 58 pre-schools, 30 for boys and 28 for girls and 40 kindergartens operating in Qatar that are linked to the Independent School system. The SEC provides strict rules and regulations regarding the required facilities for each school where all schools must have a library, a music room and both an indoor and outdoor playground (Khatri, 2014).

Since EFNE, pre-schooling has grown tremendously due to reforms initiated resulting in approximately 50 percent of appropriate age children being enrolled in preschools. Recent statistics indicate that 9 out of 10 children attend private kindergartens (Qatar National Development Strategy 2011-2016, 2011). EFNE includes strategies that define preschools as essential for supporting early childhood development, which enhances a 
Early years education in Qatar: The good practice guide in theory and practice

child's future learning ability (Althani \& Romanowski, 2013). Therefore, it is clear that Qatar's education system is very comprehensive, ranging from early childhood education through to higher level education and additional training as well (Qatar National Development Strategy 2011-2016, 2011).

Althani and Romanowski (2013) argue the current educational reform is based on a Western-style, child-centered teaching approach for preschools. Qatar's early childhood educational goals are aligned with international standards, Association for Childhood Education International, ACEI, and, specifically, ACEI Global Guidelines. In addition, Qatar's preschool educational goals/standards are aligned with developmentally appropriate practices from an international perspective and reflect the "belief that all children are entitled to basic human rights and the opportunity to develop within a safe and secure environment that values and respects individual differences" (ACEI Global Guidelines Assessment, 2011). The ACEI Global Guidelines include 76 indicators of program quality that have global relevance. How standards are met vary from nation to nation. Thus the vision and goals of the SEC reflect globally recognized standards. Publications such as The Early Years Education Good Practice Guide (GPG) play a key role in shaping early childhood education in Qatar. As stated in the GPG,

High quality Early Years educational experiences make a difference to the life-long learning, and social and emotional development of individuals. The Guide will support Early Years teachers and leaders to provide high quality programmes that:

$>\quad$ provide age-appropriate and well-resourced Early Years educational opportunities for all children based on research and knowledge about effective practice;

$>\quad$ give young children a strong foundation for future and life-long learning;

$>\quad$ ensure children have ample opportunities to develop their social competence and creativity, and

$>$ facilitate the transition from home to school to maintain supportive connections between the two crucial worlds of the child (Education Queensland International, 2009, p. 2).

Thus, the GPG coupled with national curriculum standards serves as the foundation for early childhood education in Qatar.

\subsection{The Implementation of Educational Policy}

Policy serves the purpose of confirming that actions of an organization or the individuals within the organization have a sound theoretical basis. In the context of education, policy serves as a guide that provides administrative or teaching guidelines that offer a framework for decisions and actions but do not provide the decision or appropriate action. However, the norm for educational policy production and implementation often creates a direct "top-down conception of the policy process, as if policy can "get done" to people" (Smit, 2003). Administrators, teachers and schools are often disconnected policy receivers (Bowe, Ball, \& Gold, 1992) who are required to implement policy, although they are excluded from the production of educational policy.

Research indicates that long lasting change in schools can only occur from change in the teachers' basic practices that require a redefining of the relationship between teachers, knowledge and students (Elmore, 1996). More importantly, changes in pedagogy are at the core of successful sustainable long-term educational reform (Cuban, 1988; Elmore, 1996). Fullan (2000) recognizes the need for change in pedagogy but also points out the need for viewing educational reform from three perspectives, the inside story, the inside out story and the outside in story. This enables reformers to gain a multidimensional view of reform.

The inside story involves the teachers within the school who are working at implementation and the improvement of their teaching and trying to gain understanding of their educational practices. The key is that the attempt to improve is from within the school where teachers want to change and improve, teachers strive to, 
"become assessment literate in order to be successful ... pedagogy and assessment feed on each other, through the interaction of teachers, to produce better results" (Fullan, 2000, p. 582). The key to the inside story comes from teachers who develop a learning organization that give them time to work together on solutions to educational problems. These teachers are provided with needed professional development and trusted to seek solutions. Fullan (2000) argues that the key to the inside story is reculturing not restructuring. The key to the inside story -- is not restructuring but rather reculturing, "the process of developing professional learning communities in the school. Reculturing involved going from a situation of limited attention to assessment and pedagogy to a situation in which teachers and others routinely focus on these matters and make associated improvements" (Fullan, 2000, p. 583).

Fullan's (2000) outside in story centers on the supportive framework that schools operate within. This takes the form of the organization that controls and receives performance data from schools and deals with funding. The outside in story should support decentralization while simultaneously requiring accountability. The outside framework should encourage innovation and the support necessary for schools to become effective learning organizations. For Fullan (2000), "the key concept for the outside is the external reform structure" (p. 583).

Fullan (2000) defines the inside out story of educational reform when schools are involved with the outside forces such as parents, the community, technology, government policy and the wider teaching profession. These forces are often viewed with concern and approached with caution. However, some of these forces can be allies such as parents while others can be seen as a threat or feared such as technology or new approaches to teaching for many teachers. This is where the need for the learning community within the school is vital to support teachers by providing the needed climate and professional development programs that reduce the tension and fears of developing in new professional areas. The fundamental aspect of the inside out story is that schools and teachers clearly understand how they are being assesses and measured and then teachers can "take advantage of external standards to help inform what they are doing" (Fullan, 2000, p. 582). An important point here is that the assessments must be clearly aligned with the policies and goals of educational reform.

When examining educational policies, it is important to recognize that policy, people, and places affect the implementation of policy and the key to fully understanding policy implementation is to uncover their various dimensions and how and why interactions among these dimensions shape implementation in particular ways (Honig, 2006). In the context of Qatar, the SEC and related policies, teachers and administrators and the cultural aspects of such a diverse country all place a significant role in how policy is implemented.

\subsection{Early Childhood Education In Qatar: The Good Practice Guide (GPG)}

The Early Years Education Good Practice Guide (GPG) was designed to contribute "to the Supreme Education Council reform initiative: Education for a New Era" (Education Queensland International, 2009, p. 1) The GPG was first developed in early 2007 and has gone under two revisions with the latest revision in 2009. The guide is written for all those involved in Early Years education (Pre-K: 3 year olds; Kindergarten: KG1 4 year olds, KG2 5 year olds; and Grades 1 and 2) and draws upon "research findings and professional documentation from a range of systems and regions, while attending to the culture and values of Qatar... concept of "Good Practice" is used to represent evidence-based, needs based, culturally responsive and relevant to the curriculum and functional development of the child" (Education Queensland International, 2009, p. 2).

The GPG states that the purpose of the Good Practice Guide is to provide:

$>$ A framework for policy implementation at the school and Education Institute level;

> Professional practice guidelines for implementing the Foundation Curriculum (Supreme Education Council, 2007) and alignment with the Curriculum Standards (Supreme Education Council, 2005), and

> Guidance for Early Years teachers in Independent Schools as they work towards the National 
Early years education in Qatar: The good practice guide in theory and practice

Professional Standards for Teachers and Leaders (Supreme Education Council, 2007) and professional licensure (Education Queensland International, 2009, p. 2).

Overall, the GPG is a well-researched and written document that is developmentally sound. The guide provides a summary of the research factors that are beneficial for Early Years Education and a well-developed set of values and goals related to effective Early Years practice. The Foundation Curriculum and the Curriculum Standards included provide specific guidance on program practices that promote the learning outcomes. The GPG was written with the Qatar educational reform in mind. The GPG provides 12 areas of Early Years good practice that are aligned to the Qatar National Professional Standards for Teachers and Leaders, and school policies that support and strengthen Early Years educational practice are provided (Education Queensland International, 2009).

\subsection{Early Childhood Education In Qatar: Curriculum Standards}

The philosophy underlying Qatar's curriculum standards is that "today's students must have a high degree of competence in all these subjects, and must benefit from the best opportunities in higher education, if they are to compete successfully in the worldwide economy" (Evaluation Institute, 2004, p. 9). Furthermore,

the standards are based on the premise that all Qatari students are capable of learning successfully and of achieving high levels of performance. The standards are aligned to the expectations found in those countries that demand the most of their students, including those that achieve excellent results in international tests (Evaluation Institute, 2004, p. 9).

Currently, the curriculum standards implemented in Qatar "demonstrate what Qatari students should know, understand and be able to do by the end of each grade from Kindergarten to Grade 12" (Evaluation Institute, 2004, p. 9). Furthermore, the standards were developed and written in order to assist "each Independent School to plan its curriculum, to guide writers of teaching and learning materials, and to inform the design of tests and examinations" (p. 9). The standards cover four subjects: Arabic, English, mathematics and science.

\section{Study Overview}

In this study, we provide, as previously discussed, what Fullen (2000) terms the inside story by describing teachers' perspectives and experiences working at the implementation of educational policies and practices. Thus, we focus on how teachers in selected Qatar kindergartens are implementing educational policy within their classrooms. In particular, we center this study on Qatar's Supreme Education Counsel's The Good Practice Guide (GPG) developed by an international education consulting firm and developmentally appropriate. To access this inside story, the goal was to conduct focus groups and interviews with these same teachers and academic coordinators in order to discuss their views and understandings of The Good Practice Guide and their implementation of the GPG in their school and classrooms. These focus groups discussed challenges and obstacles that the teachers face regarding implementation.

We also attempt to provide Fullan's (2000) outside in story examining and discussing the supportive framework that schools operate within. We address this by examining the school facilities, conducting classroom observations and utilize the interviews and focus groups to assess the support that is provided for these teachers. In addition, we provide discussion centering on Fullan's inside out story of educational reform by addressing some of the outside forces that play a significant role in the teaching profession. Finally, we utilize the findings from classroom observations and focus groups to provide recommendations that could be used to improve the implementation of educational policy (the GPG) into kindergarten classrooms in Qatar. Since there is no previous research that examines the implementation of particular policies of Qatar's Educational Reform at the early childhood level, a contribution of our study is that it provides insight regarding issues that aid or hinder theory moving into practice at the classroom level. We expect that the degree of implementation and the challenges and obstacles that teachers face will be context specific to Qatar. 


\subsection{Description of the Classroom System}

The school system in Qatar is gender segregated where female students attend schools taught by female teachers, and vice versa. The only exception is in some K-6 boy schools some classes are taught by female teachers. On average there are 27 students placed in each kindergarten classroom and kindergartens range from 4 to 7 classrooms per school, with children ranging in age from 4 (KG1) to 5 (KG2). There is, generally a science, Arabic, or English teacher in each classroom at one time with an assistant teacher. The teacher assistant however has a break during the science class and the English teacher assists during that time, because although science is taught in Arabic, there is certain English terminology incorporated into the science classes. Also, most classrooms provide a teaching assistant who is available to assist students with special needs. Thus the adult-child ratio per classroom generally averages one adult per 8 to 10 children.

\section{Methodology}

Currently, there are few studies, if any that examine policy and pedagogical theory implementation into kindergarten classrooms in Qatar. Thus, in order to examine how polices and teaching theory is implemented, it is vital to begin by examining the perspectives of coordinators and teachers who actually work in these schools.

The core research objective for this study is to examine how early childhood teachers are implementing the GPG. In order to accomplish this, several additional objectives will guide this study. These are:

$>$ To determine the challenges that early childhood teachers face when implementing the GPG.

$>$ To examine the support system for early childhood education.

To provide recommendations for improvement of the implementation of the GPG.

\subsection{Data Collection}

This study is framed on the fundamental aim of qualitative and observational research. That is, to provide readers with an accurate understanding of the perspectives of those involved in a particular situation. For this study, data were collected from focus groups with 22 kindergarten teachers/academic coordinators and conducted classroom observations to determine the practices being utilized in kindergartens, obstacles that prevent teachers from implementing the GPG and to seek possible recommendations regarding the implementation of the GPG. Findings will be used to offer recommendations to improve policy implementation.

In qualitative inquiry, there are no set rules for sample size. Sample size depends on several issues such as what the researcher wants to know, the purpose of the inquiry, what will provide credibility, and what is possible with the available time and resources (Patton, 1990). Researchers should interview from 5 to 25 individuals who have all experienced the phenomenon under study (Polkinghorne, 1989). Thus, focus groups and interviews were conducted with 22 teachers and coordinators in selected kindergartens since these are the individuals who have experienced the phenomenon, in this case policy implementation. The sample included the 3 municipalities with large population pockets, including the capital city Doha 4 schools and 1 school in Al Wakra south of Doha.

\subsection{Classroom Observations}

As previously noted, the kindergarten schools on average consists of 4 to 7 classrooms with a library and indoor and outdoor play areas to support physical development. The researchers utilized the ECERS-R (see Cassidy et. al, 2005; Sylva, Siraj-Blatchford, \& Taggart, 2003) as a framework for assessing the overall environment of each Kindergaten visited. In terms of rating, consensus among the researchers was easily reached, with all researchers rating the environment minimal to excellent in all relevant domains. Each classroom includes the following learning centers (referred to at the schools as "The Discovery Corners"): science/math, art, dramatic play, literacy with an outside play area attached to each classroom. Due to the weather in Qatar, 
which can be quite hot during several months of the year, schools were designed to accommodate large motor skill development within the school building itself. So, given both space and activities, physical development is a strong component of the kindergarten program. Each classrooms is designed to accommodate the various learning centers, as listed, however, in most cases, the classrooms are a bit small for more than 20 children. Thus, although each classroom had a literacy area, the space does not provide a 'quiet area for reading, and space per learning center is limited to only a few children participating in an activity at one time. The teachers accommodate the space restrictions by rotating the children through the various center activities, but in doing so, somewhat limit children's free choice.

\subsection{Data Analysis}

Qualitative data analysis can be defined as analyzing data that is then organized into convenient components. From these organized components, patterns that illustrate what is important and what should be communicated to others are identified and developed (Bogdan \& Biklen, 2002). In this study, all data were collected and examined in the content of the core research objectives and subsequent research objectives. This required researchers to select, focus, condense and transform the data. This process was guided by utilizing appropriate data to respond to the various research objectives. Researchers analyzed the data and identified and organized emerging themes, patterns, and connections (Denzin \& Lincoln, 2007; Taylor-Powell \& Renner 2003; Miles \& Huberman, 1994). The themes were then content analyzed selecting relevant quotes that were used to support or refute the findings. The reasoning is to develop a detailed and accurate account of the teachers' and coordinators' understanding of the issues involved in educational reform. In what follows, the themes that emerged from these interviews are presented and developed followed by discussion and recommendations. Throughout the process, we constantly engaged in self-reflection in order to provide a more complete account of participants' responses.

\section{Findings}

The following sections of this article discuss the findings from the interviews and focused groups, classroom observations and school visits and our own personal reflections regarding the use of the GPG and kindergartens in Qatar. In what follows, we attempt to examine and discuss both the inside and outside stories in order to provide a more holistic view of early childhood education occurring in Qatar today.

\subsection{The Outside in Story}

Part of the outside in story is the Supreme Education Council (SEC) the governmental body that oversees and provides support for all kindergartens in Qatar. At the start of the Education for a New Era, the SEC took a decentralized approach to Early Childhood Education by providing teachers with a great deal of freedom and autonomy to develop curriculum and instruction for their schools and classes. The goal was to allow for innovation and the support necessary for schools. However, issues with accountability and quality of the curriculum and instruction forced a more centralized system imposed by the SEC and also the development of the GPG and professional standards.

Furthermore, the SEC is responsible for the physical aspects of the building and our observations indicated that all schools were well designed and equipped. It was clear that the government had designed developmentally appropriate indoor and outdoor areas to enable teachers to implement of The Good Practice Guide (GPG). The classrooms at each school were divided into learning corners and as researchers, we would argue that each school was developmentally appropriate and supplied with needed facilities and resources in order to provide sound educational opportunities.

The SEC provides national curriculum standards and professional standards for teachers. Accountability for these standards is also in the realm of SEC responsibilities. To continue their ongoing support, the SEC offers teachers with extensive professional development that provides teachers with the knowledge, skills and dispositions for effective early childhood teachers. In addition, coordinators working in the schools are supported 
Al-Thani, T., Al-Muftah, E., Romanowski, M. H., Coughlin, C., \& Abuelhassan, H.

and provided with continued professional developed opportunities by the SEC and are in the schools to provide teachers with continuous support.

\subsection{The Inside and Inside Out Story: Familiarity with the GPG}

As previously mentioned, the SEC provides a well-developed and developmentally sound educational document (The Early Years Education Good Practice Guide) to guide the curriculum and instruction in kindergartens in Qatar. When asked about their familiarity with the GPG, most school coordinators and principals were aware of the specific details of the GPG and most teachers were quite familiar with the document. However, the majority of teachers knew little about the specific content of the GPG and how the GPG should be shaping their teaching. However, those who were most familiar with it tended to state that the GPG was "excellent," "useful for teaching," and that "the students can benefit from the GPG." For example, one teacher stated:

[the GPG] provides different strategies and how to deal with different types of students....it is useful for the teacher and addresses the normal student, the student with a disability, and the talented student.

Although these teachers provided a positive view of the GPG, there was also a teacher who was not aware of the GPG, while another stated, "I have not read it." Some teachers commented that it was too long and that they did not have the time to look at it in detail, but that they were familiar with its content. This demonstrates the rather wide continuum that exists among teachers regarding their perception and use of the GPG. Although the GPG is a well-written and useful document developed for the educational reform, it is evident that without teacher acceptance and use, little will change in the classroom resulting in a limited impact of the educational reform.

More importantly, the issue here is linked to the wider teaching profession regarding the qualifications and preparation of teachers. In this study, ten of the teachers interviewed had a degree in education. An important point is that in Qatar, Qatar University is the only national university and the only university that prepares teachers. Prior to offering a diploma program in early childhood education in 2002, there was a track within the home economics program that offered some early childhood courses. This track ended in 1997. This lack of opportunity for education for preschool teachers has resulted in a lack of qualified teachers (Al Thani \& Romanowski, 2013). Thus, most preschool teachers in Qatar lack the background and skills needed to fully utilize the GPG or provide resources to students, and have difficulty applying GPG theories to practical classroom situations. This information may provide insight into why a continuum exists regarding teacher use of the GPG. More importantly, this important piece of knowledge might explain not only the use or lack of use of the GPG, but also the manner that the GPG is implemented.

\subsection{The Inside and Inside Out Story: Implementation of the GPG}

Concerning the implementation of the GPG, this discussion provides the inside and inside out story regarding the various aspects of the GPG that play a significant role in the classroom. Questions based on concepts that were derived from the GPG were asked of all interviewees, whether they were familiar with the GPG or not.

First, we addressed teaching strategies. Participants indicated that there were several teaching strategies in the GPG that they currently implement in their classroom teaching. Teachers discussed these strategies, which included brainstorming, learning through song, discovery learning utilizing "The Discovery Corners," the use of play, and integrating the outdoor environment into their teaching. Nonetheless, when teachers were asked about specific concepts in the GPG and how they were being implemented, different interpretations of the concepts appeared. For example, when asked about teacher-guided play, the teachers tended to give examples of usual day-to-day activities, not of play that is structured and guided by adults. These different understandings of the concepts in the GPG could be tied to its use of abstract concepts, which was critiqued by some of the 
interviewees (later discussed in the challenges section of this paper). It is clear that teachers implement some of the suggested teaching strategies, but most of these teachers also feel that the SEC plays a significant role in providing resources, strategies, and the standards that are used in the classrooms. These examples point back to the lack of qualified teachers in these schools. Not only is there a poor implementation of the GPG but there is also a reliance on the SEC to provide them with what needs to be taught and how it should be taught.

Second, a key aspect of the GPG is the ability for teachers to be flexible in order to accommodate children's needs and interests. When asked about their flexibility, participants believed that they were flexible but indicated that their flexibility was directly influenced by Qatar's preschool standards and goals and by the SEC documents. One teacher stated, "the [weekly lesson] plans come from the SEC and also the months' themes. But we can develop ideas and resources." This flexibility is important, and not simply done haphazardly. One teacher stated:

\section{There is flexibility in reflection. For example, I can change the lesson plan but I need to reflect on it to explain why I changed it. That way if anyone walks into the room and wants to understand why I changed the subject they can see that in my reflection.}

This teacher indicated that there is flexibility in her teaching but that there must be sound reasoning behind any changes she makes from the prescribed curriculum. However, when it comes to flexibility and the standards, we received mixed messages from teachers. Interestingly, other teachers noted they were expected to finish different lessons on time and that there was no room to change any of the required content. A teacher stated, "the standards which we follow are [embedded in] the Get Smart [curriculum]. We don't have room for change." This teacher indicated the need for flexibility in standards directly, stating that, "Standards must allow for a flexible strategy." This teacher's point again is tied to the pace at which the policies change. Although originally the teachers had complete control over the materials and strategies used in their classrooms, the current standards and curriculum available to teachers encompasses most of the material that teachers were required to develop early in the reform.

The GPG emphasizes a vital aspect of curriculum development. That is, the curriculum should be based on the interests and needs of the children. These teachers indicated that the curriculum utilized in these schools is not only developmentally appropriate and child centered but that the English curriculum "is built on the child's interest." However, some coordinators noted that the Arabic curriculum needed further planning, to allow for more flexibility, so that "we all contribute to the curriculum."

When asked about these pedagogical issues, teachers stated, "It is child centered. For example, you play a game with the child"; "the [Qatari preschool] standards are based on playing and the children's interest"; and "The standards are developmentally appropriate." Like the concept of teacher-guided play, the concept of building the curriculum on the interests of the children was understood differently by different teachers.

Many teachers indicated that the standards play a major role in shaping the curriculum. For example, one teacher stated, "The implementation of the lessons is guided by both the [preschool] standards and the students' interests. It is guided by the student level, but there is pressure to implement the standards." Another teacher stated, "it is the standards that guide lessons. There are several standards, and the teacher is restricted to those standards." One teacher described the difficulty with the emphasis on standards as follows: "it is guided by the standards, and standards are above the student's ability level, but it is compulsory to implement them."

In summary, many of the concepts put forward in the GPG (e.g. child-centered teaching, play-based instruction, and differentiated learning) were familiar to the teachers. Nonetheless, individual teachers understood these concepts differently. Yet at other times, the standards and goals were seen as challenges. In the next section, we discuss some of these challenges that standards seemed to create for the teachers. 


\subsection{The Outside in and Inside Out Story: Challenges and obstacles facing GPG implementation}

Qatar National Curriculum Standards. Teachers and coordinators were clear that implementing the GPG was difficult at times and that they faced various challenges. The first challenge was the number of curriculum standards that the SEC expects teachers to cover in a short time. The curriculum standards for kindergarten are specified in relation to the following discipline areas: Science, Math, English and Arabic (see Supreme Education Council. Curriculum Standards: Kindergarten). Some of the teachers noted that the standards are too high for kindergarten students. For example, one of the most experienced teachers interviewed (who had been teaching for 17 years) noted, "This must be in the standards' level. They are too high. We would like to focus on behavioral skills at this stage, not writing". Even experienced teachers struggled with the level and use of standards which brings us back to the point of the unqualified or inexperience teachers and the difficulties they might face and how they deal with these challenges.

There was one exceptional school at which the standards and goals for the students were perceived as low. Nonetheless, during a visit to that school's library, the coordinator noted that the level of the Arabic textbooks was too high for the students. This could indicate that textbooks are not in line with the standards the government set.

Classroom size. Another aspect of the inside, inside out stories deals with the classroom system. A second issue, raised by almost all interviewees, was the large class sizes. Most of the schools visited had over 25 students per classroom, which presented challenges for many of the teachers. This obstacle is not limited to applying the GPG but is transferable to a variety of pedagogical concerns. Teachers in this study indicated that a classroom size of 15 students is ideal, but that they could meet the requirement more easily if classrooms were limited to no more than 18 students. Interestingly, this figure was also what the reform plan had hoped for, at least on paper. Nonetheless, due to population growth in the country, kindergartens today are sometimes required to take up to 30 students per classroom, as was the case at one of the schools visited. A consistent comment by teachers was that the number of children per classroom was too large. Each classroom consists of learning centers (science, literacy, dramatic play, art, etc.); and as previously noted, given the size of the classroom in relation to the number of children, the learning centers are somewhat limited in terms of the number of children who can be in each center at one time.

This is significant since several of the teachers pointed out the need for meeting individual student needs and interests. One teacher stated, "it [implementing GPG] is especially challenging since every student is different and they ask a lot of questions... there is need for differentiated instruction and it is hard to do that with large numbers of children per classrooms". The issue of class size raises an important point. Without an educational structure that is conducive to the application of the GPG or other educational policies, it is very difficult to effectively carry out sound pedagogical practices. In this context, the large class size limits the use of sound educational theories and practices.

The schools, however, utilize their space wisely in that the entire school is used to accommodate various activities. For example, in concert with a library room, as well as large and small motor play areas, each school also provides a designated eating area. These rooms, areas provide for an excellent extension of the classroom. Each school visited for this study demonstrated the highest standards in terms of cleanliness. There is an indication that some schools make use of these spaces more than others. All materials were well cared for and in good working order. The kindergarten school buildings are something Qatar can be proud of and would be an envy of many countries.

Workload. The third common issue that was raised regarding the GPG is the issue of workload. Teachers mentioned "SEC requirements," "weekly plans," "reports every month," and "child improvement weekly reports" frequently. These teachers argued that they face numerous tasks in addition to teaching, which is a significant obstacle for the implementation of the GPG. 
There is no time for preparation because there are too many papers, in addition to spontaneous observation forms for each student and pre/post test and observation forms. Every month there is a report on each student, and weekly as well. So as a teacher I am faced with a dilemma, focus on [developing] the content or filling out all these observation forms.

Teachers indicated that there is a lot of paperwork they are required to complete in a specific time. This work uses teachers' time and reduces the time they can spend on other educational development tasks, such as implementing the GPG.

Interestingly, at one of the most outstanding schools visited, the coordinators noted that they did not require the teachers to actually fill out all the expected paperwork because, in their professional opinion, not all the students needed detailed reports and they preferred to have teachers engage in lesson planning.

Outdated. One of the clearest points made on the implementation of the GPG came from a focus group with coordinators at one of the oldest kindergartens in Qatar. She argued "it (GPG) needs modifications ... The GPG is outdated because the SEC provides most of the information [weekly lesson plans and books] and the teacher does not need to develop her own curriculum." This was later echoed in the recommendations of these coordinators: "If it had more techniques for the teachers it would be useful. Since previously we had to develop our curriculums it was different. Now with everything available it can be updated."

This comment reflected the speed at which policies in Qatar were being changed. The coordinators had pointed out that early in the "Education for a New Era" reform plan, the schools were expected to develop their own curriculums and this guide was meant to help the teachers develop a best practices curriculum and strategy. Nonetheless, now that the SEC provides teachers with weekly plans and other detailed curriculums, the GPG was not necessarily all that helpful.

\subsection{The Inside and Inside Out Story: Role of the Academic Coordinator}

Early in the school visits, the coordinators were mentioned by the teachers as playing a major role in lesson planning and, hence, in the integration (or not) of the GPG concepts. According to the teachers, the coordinator plays a quite dominant role in the schools visited. As one teacher stated, "the coordinators do everything." The position of coordinator is demanding, since coordinators are required to supervise teachers, supervise plans, help teachers prepare, conduct workshops, and, as one teacher stated, "whenever we need something we go to the coordinators. From them, we get suggestions for activities and also feedback."

Hence, when it comes to the different concepts in the GPG such as adult-guided play, child-centered teaching, etc. the coordinator plays a major role in planning. After receiving the weekly plans from the SEC that specify which preschool national standards and goals are expected to be fulfilled, which activities are suggested to accomplish those goals, and under which themes these goals are to be achieved; it is the coordinator who meets with the students and plans the day-to-day lessons and activities, aligning them with the curriculum.

Therefore, the subject coordinator plays a pivotal role in relaying SEC documents, including the GPG, to teachers. At various times, the coordinators have been invited to meet with the SEC to discuss the policies. Two coordinators stated, in a focus group, "the meetings with the coordinators/SEC are not of high standards as expected. For example, the meetings that deal with the standards and implementation are not helpful" and "there needs to be a third coordinator that is certified in science or math education."

One coordinator supported one of the above issues by stating, “...we (the English coordinators) do not have the level of knowledge necessary to support and evaluate science and math teachers." Therefore, it is hard for the English coordinators to give the necessary pedagogical support to science teachers. This again ties in with the changes in policies that occurred in kindergartens in the past couple of years. While previously, science was taught entirely in English, currently it is being taught in Arabic. However, certain English terminology is 
Al-Thani, T., Al-Muftah, E., Romanowski, M. H., Coughlin, C., \& Abuelhassan, H.

incorporated into the science curriculum. Therefore, the previous integration of English, science, and math, under the supervision of one teacher, has been discontinued.

\subsection{The Inside, Outside and Inside Out Stories: Additional Issues}

When participants were asked about their recommendations, their responses raise additional issues regarding outside forces such as parents and domestic servants, the role of teachers and the use of curriculum standards that must be considered. First, there is a concern about the level of the standards and the GPG guide itself. One participant questioned the level of the standards and suggested that the current standards are too high and advanced for their students. Coupled with this issue that teachers have difficulty utilize the GPG and curriculum standards. Teachers comments such as "It is difficult the way it is presented;" "It [GPG] should give teachers more freedom;" "the given concepts are big, theoretical, and non-practical; and "it is challenging to implement it. If it had more techniques for the teachers it would be useful" all demonstrate the challenges these teachers face but also hints toward the lack of skills and abilities to unpack these concepts and theories and utilize these in the classroom.

There was a concern regarding the role of parents and the heavy reliance on domestic help in Qatar. These teachers raise an important issue here. The use of domestic help has been criticized in regarding to issues of language and schooling. El-Haddad (2003) argues that this dependency of Gulf families on domestic servants "has to do more with the urban culture that was introduced by the financial provisions resulting from increased wealth" (p. 5). Regarding the role of domestic servants, Chatriwala (2012) points out the Qatar's Permanent Population Committee "has recommended decreasing the Qatari household dependency on maids, most local families say that maids are inevitable to keep the house running." The high reliance on domestic maids and other servants in the upbringing of children have negative consequences (Evans, Powell-Davies \& Chung, 2010, p. 29). That is, the socialization of children and the influence of the various cultural values and language through the domestic servants in the Qatari household having serious consequences on Arab values and language having negative effects on Arab children's behavior (El-Haddad, 2003). In addition, "most domestic servants (maids) are not trained to raise children or to care for them. They add that the characteristics of the maids, such as education, language, religion age, don't qualify them to raise children" (El-Haddad, 2003, p. 5). The reliance on domestic help not only impacts language and behavior but also could play a role in parental involvement in schools.

\section{Discussion}

This research is neither a comprehensive look at kindergarten in Qatar nor is it our intent to achieve this goal. Rather because there is little research conducted in kindergartens in Qatar, we attempt to provide a snapshot of what is occurring in several schools centering on Fullan's (2000) three stories. More importantly, there are few if any studies that center on the implementation of educational theory in the kindergarten classroom. However, there is evidence that the SEC has put into place appropriate and developmentally sound practices for Qatar kindergartens. Each school has the physical facilities needed to implement an excellent early childhood program. The GPG also provides developmentally appropriate early childhood theories and practices that can be implemented and transferred into the Qatari context.

Throughout the interviews and classroom observations, it is clear that the GPG plays a role in shaping curriculum and pedagogical practices however, the curriculum standards seem to take precedent over all else. Although standards are important, teachers seems to obsess on the standards and seem to lack an understanding as to how standards can and should be integrated within the GPG, curriculum and developmentally appropriate practice; many teachers seem to lack this understanding and at times the knowledge, skills and background to utilize both standards and the GPG in an effective integrative manner.

Although the GPG contains 61 pages, the issue may not be solely that teachers do not read it but rather that they lack the prior knowledge and complex understanding of the concepts necessary to apply recommended 
practices to the classroom. One teacher pointed out that:

the GPG is not presented in a smooth and easy way...It also contains rigid standards that I do not know how to implement. For example, feedback....How do I implement this concept? ...So it is not clear how these good practices can be implemented practically in the classroom.

This concern expressed by participants raises an important issue regarding the educational background of early childhood teachers in Qatar. According to the SEC, more than 30 percent of teachers in Qatar are not qualified to teach; 31 percent of teachers in Qatar have no formal qualifications to teach, and 35 percent of these teachers are teaching in independent schools ("Above 30 \% teachers," 2011). Al Thani and Romanowski (2013) point out:

[there] is no centralized system for the recruitment of early childhood teachers in Qatar, and the lack of qualified teachers is problematic for some schools. Schools are forced to select and hire the best teachers available and at times, these are under or unqualified.

It was evident from the school interviews that teachers who had a background in education, and who had more work experience, seem to be implementing the concepts in the guide even if they were not familiar with it, and this was especially true for those with professional training in early childhood education.

All this places the coordinators in the position of mediator of the GPG and the National Curriculum Standards. These findings indicate that the SEC and coordinators play a dominant role guiding the curriculum and teaching in Qatar kindergartens and teachers depend on both for guidance and direction in their teaching. This role as mediator can reduce these teachers to technicians that carry out prescriptions and objectives from others rather than developing pedagogies themselves, which requires teachers to read, understand and utilize best practices that are found in the GPG.

In addition, our classroom observations indicated that there is a great deal of use of handouts where all students are doing the same task at the same time. There is a concern that teachers are too focused on the curriculum standards and that there is a great deal of teacher directed teaching and little time is provided for children to interact and communicate with each other. In observing the classroom, children were seen working independently, even in group settings, and very much focused on doing what was expected to be completed. Communication and social skills are set aside in order to have good class management. This emphasis on getting the work done, controlling the classroom and teacher-centered teaching seems to be directly related to the pressure from the SEC for schools and teachers to meet the standards.

\subsection{Recommendations}

There is no doubt that implementing an Early Childhood Education program demands a collaborative effort of all stakeholders. This includes parents, teachers, school leaders, students, community members and government entities. Although the government must provide all necessary teaching and learning resources, the role of coordinators and teachers cannot be overemphasized. Thus there are several recommendations that emerge from this study that would provide useful. In Qatar, there is little doubt that excellent facilities and a solid practice guide are provided for kindergartens and teachers. Based on this, it is vital that kindergarten teachers have a degree in early childhood education and are well equipped to read, understand and apply developmentally appropriate educational theories to the classroom. This requires that new teachers complete a bachelors or at minimum a diploma in early childhood education. This education provides teachers will the knowledge, skills and dispositions that enable them to effective implement theory to practice. However, we know from education policy implementation literature that simply having access to resources does not necessarily cause the resources to be utilized well (Grubb, Huerta, \& Goe, 2006; Honig, 2006).

Since the above takes time, there needs to be effective professional development that does not simply 
provide "training" instead of education for teachers. It is important to recognize "the major concern with standards-based educational reforms is that educators' work is in jeopardy of being reduced to technical activities or skills designed to produce outcomes based on professional standards" (Romanowski, 2013, p. 6). This is the case here where teachers are attempting to simply "carry out" pre-determined educational objectives without possessing the knowledge and skills needed to be able to unpack curriculum standards, develop lessons and assess student progress. Therefore, professional develop, designed to meet this challenge, needs to understand that that teachers play a fundamental role in educational reform and stop providing workshops that deliver teachers a preset package of pedagogical recipes that are technically carried out in the classroom. Rather professional education must develop the pedagogical knowledge and skills in teachers so they are able to act as teachers and not simple technicians: "uncritical, "objective," and "efficient" distributors of information" who neglect the more critical aspects of culture and schooling (Giroux \& McLaren, 1996, p. 304), and this is especially true in early childhood as teachers and education as experienced by children at this age sets the tone and expectations for future educational experiences.

Second, principals and coordinators in these schools must develop the knowledge and skills needed so they can engage in instructional supervision that centers on teachers' growth and development. This must include developing teachers' ongoing reflective inquiry skills and must promote professional growth and renewal. Effective supervision fosters a critical examination of teachers' beliefs about teaching and learning as well as movement toward similarity of beliefs and practice.

Third, academically it is accepted that large class sizes reduces learning. As noted by the teachers, class size is an issue. Classrooms with no more than 18 children allow for better instruction and an overall better learning environment for the children. This should be a priority of the SEC and schools in order to provide better educational opportunities.

Fourth, there is a need within Qatar's educational reform for an increase in parental involvement in their children's education. In order to develop a caring community around students, teachers, parents and students must be viewed, as partners in education and parents must be an integral part of the school. Children learn and grow in schools, communities and at home therefore it is vital for a positive and active parental role in education.

Finally, teachers need to be able to develop the viewpoint that high academic and curriculum standards are an essential part of an effective school. However, standards are designed to serve teachers and students in order to promote learning. Teachers and students should not serve the standards blindly following and implementing requirements. Rather, every educational policy implemented in schools must serve to improve teaching and make learning more effective.

\section{References}

Above $30 \%$ teachers not qualified. (2011, September 4). The Peninsula. Retrieved from http://thepeninsulaqatar.com/news/qatar/163929/above-30pc-teachers-not-qualified

ACEI global guidelines assessment. (2011). Washington, DC: Association for Childhood Education International ( $3^{\text {rd }}$ ed.). Retrieved from http://acei.org/programs-events/global-guidelines.html

Althani, T., \& Romanowski, M. H. (2013). Neoliberalism and Qatari preschools: A comparative study of England and Qatar. The Near and Middle East Journal of Research in Education, 13(2). http://dx.doi.org/10.5339/nmejre.2013.2

Bogdan, R. C., \& Biklen, S. K. (2002). Qualitative research for education: An introduction to theory and methods (4th ed.). Needham Heights, MA: Allyn and Bacon.

Bowe R., Ball, S., \& Gold, A. (1992). Reforming education and changing schools: Case studies in policy sociology. London: Routledge.

Brewer, D. J., Augustine, C. H., Zellman, G. L., Ryan, G. W., Goldman, C. A., Stasz, C., \& Constant, L. (2007). Education for a new era: Design and implementation of k-12 education reform in Qatar. Santa Monica, 
Early years education in Qatar: The good practice guide in theory and practice

CA: Rand Corp. Retrieved from http://www.rand.org/pubs/monographs/MG548/

Cassidy, D., Hestenes, L., Hedge, A., Hestenes, S., \& Mims, S. (2005). Measurement of quality in preschool child care classrooms: The early childhood environment rating scale - revised and its psychometric properties. Early Childhood Research Quarterly, 20(3), 345-360.

http://dx.doi.org/10.1016/j.ecresq.2005.07.005

Chatriwala, O. (2012). Maid abuse in Qatar: A growing problem. Doha News. Retrieved from https://dohanewsco.wordpress.com/tag/domestic-workers/page/2/

Cuban, L. (1988). A fundamental puzzle of school reform. In A. Lieberman (Ed.), Schools as collaborative cultures: Creating the future now (pp. 71-77). New York: The Falmer Press.

Denzin, N. L., \& Lincoln, Y. (2007). The landscape of qualitative research (3rd ed). New York: Sage Publications.

Education Institute. (2004). Curriculum standards for the State of Qatar: Grades K to 12. Doha, Qatar. Retrieved from http://www.ibe.unesco.org/curricula/qatar/qa_al_eng_2004_eng.pdf

Education Queensland International. (2009). The early years education good practice guide. U.K.: Australia \& Nord Anglia Limited.

Elmore, R. (1996). Getting to scale with food educational practice. Harvard Educational Review, 66(1), 1-26. http://dx.doi.org/10.17763/haer.66.1.g73266758j348t33

Fullan, M. (2000). The three stories of educational reform. Phi Delta Kappan, 81(8), 581-584.

Giroux, H. A., \& McLaren, P. (1996). Teacher education and the politics of engagement: The case for democratic schooling. In P. Leistyna, A. Woodrum, \& S. A. Sherblom (Eds.), Breaking free: The transformative power of critical pedagogy (pp. 301-331). Cambridge, MA: Harvard Education Press.

Grubb, W., Huerta, L., \& Goe, L. (2006). Straw into gold, revenues into results: Spinning out the implications of the improved school finance. Journal of Education Finance, 31(4), 334-359.

Honig, M. I. (2006) Complexity and policy implementation: Challenges and opportunities for the field. In M. I. Honig (Ed.). New directions in education policy implementation: Confronting complexity (pp. 1-23). Albany, New York: State University of New York Press.

Khatri, S. S. (2014). Supreme Education Council: 13 new schools to open in Qatar this fall. Doha, Qatar; Doha news. Retrieved from http://dohanews.co/supreme-education-council-13-new-schools-open-qatar-fall/

Miles, M. B., \& Huberman, A. M. (1994). Qualitative data analysis (2nd ed.). Newbury Park, CA: Sage.

Patton, M. Q. (1990). Qualitative evaluation and research methods (2nd ed.). Newbury Park, CA: Sage Publications, Inc.

Polkinghorne, D. E. (1989). Phenomenological research methods. In R. S. Valle \& S. Halling (Eds.), Existential-phenomenological perspectives in psychology (pp. 41-60). New York: Plenum. http://dx.doi.org/10.1007/978-1-4615-6989-3_3

Qatar National Development Strategy 2011-2016. (2011). Retrieved from http://www.gsdp.gov.qa/gsdp_vision/docs/NDS_EN.pdf

Romanowski, M. H. (2013). The Qatar national professional standards for school leaders: A critical discourse analysis using Habermas' theory of knowledge constitutive interests. International Journal of Leadership in Education. http://dx.doi.org/10.1080/13603124.2013.814808

Smit, B. (2003). Can qualitative research inform policy implementation? Evidence and arguments from a developing country context. Forum Qualitative Sozialforschung / Forum: Qualitative Social Research, 4(3). Retrieved from http://nbn-resolving.de/urn:nbn:de:0114-fqs030363

Supreme Education Council. (2005). Curriculum Standards. Retrieved from http://www.teachers.net.qa/

Supreme Education Council. (2007). National Professional Standards. Retrieved from http://www.teachers.net.qa/

Supreme Education Council. (2012). Curriculum standards: Kindergarten. Retrieved from http://www.sec.gov.qa/En/Education/Pages/GradeAndSubject.aspx

Supreme Education Council. (2012). School Lists. Retrieved from http://www.sec.gov.qa/En/ServicesCenter/Pages/QatariSchoolsListing.aspx?Gdr=3\&Grd=5

Sylva, K., Siraj-Blatchford, I., \& Taggart, B. (2003). Assessing quality in the early years: Early childhood environment rating scale: Extension (ECERS-E), four curricular subscales. London: Trentham Books. 
Al-Thani, T., Al-Muftah, E., Romanowski, M. H., Coughlin, C., \& Abuelhassan, H.

Taylor-Powell, E., \& Renner, M. (2003). University of Wisconsin extension program development and evaluation. Analyzing qualitative data. Retrieved from

http://learningstore.uwex.edu/assets/pdfs/g3658-12.pdf 